THURSDAY, NOVEMBER 23, I9II.

\section{HUMAN GEOGRAPHY.}

Influences of Geographic Environment. On the Basis of Ratzel's System of Anthropo-Geography. By Ellen C. Semple. Pp. xvii +683 . (New York: Henry Holt and Co.; London : Constable and Co., Ltd., I9II.) Price 4.00 dollars net.

THE influence of geology on that part of geography which deals especially with the forms of the earth's surface, and of mathematics on the measurement and representation of that surface, have given a definiteness and precision to the inorganic side of the subject which are less evident in the geographical study of man and of his relations to the region in which he dwells. In German the work of Ratzel has long furnished a basis for the scientific development of this part of the subject, and though his "Anthropologie" is rather a collection of brilliant essays than a logical and even treatment of this vast subject, its influence on subsequent workers has been far-reaching. In English such treatment of the subject in a scientific manner on a like scale has not been attempted, and the organic side of geography has been delayed in its scientific development here by its absence. Miss Semple's volume is therefore particularly valuable, especially as it is not simply a restatement of the principles embodied in Ratzel's work but comprises such amplification of some portions and abridgment of others as were necessary to make a more even presentation of the subject; at the same time as much evidence as possible of typical peoples of all races and all stages of cultural development living under similar geographical conditions has been incorporated.

A short account of geographical factors and influences serves as an introduction to the subject, in which the continuous operation of geographical conditions on man is shown, and their importance in the history of peoples is emphasised. These influences are classified into the physical effects of environment; the psychical effects, which are bound up in many physiological modifications, and help to differentiate peoples and races in point of temperament; the economic and social effects; and, lastly, the influence of the features of the earth's surface in directing the movements and the ultimate distribution of mankind. From this general statement of the scope of the subject illustrated by numerous instances from the history of peoples of all stages of development we pass to the results of environment as seen in general location; here the relations of a society or state to the land come first, since in geography a human group is not conceivable apart from the land on which it dwells.

Such considerations lead naturally to the more definite treatment of the geographical significance of environment in the bearings of geographical location, the influence of geographical area on its inhabitants, and the various types of geographical boundaries which exist. The examples which support and illustrate the treatment of these subjects are drawn from primitive races, semi-civilised peoples, and the civilised nations, from the races of the past as well as of the NO. 2 I95, VOL. 887 present, so as to show the importance of taking into account the stage of culture and world-relations when drawing deductions from the facts of geographical environment. The aspects of specific location are next discussed, and the part played by seas and oceans, rivers and lakes, by continents and islands, plains and deserts, mountain barriers and their passes is explained as influencing the distribution, development, and movement of the peoples inhabiting them. The people of the coast, island races, and mountain tribes are thus investigated in order to show the effects which have been produced on them by their environment.

In this way and with the aid of a full bibliography at the end of each chapter a very large amount of information relating to the influence of the earth's surface on its population has been collected and presented in a very convenient form. Definitions and systematic classification have been avoided intentionally from the conviction that the subject is being but gradually evolved, and has not yet reached a stage at which such can be usefully introduced, but some provisional efforts in this direction would have assisted the geographer who avails himself of the mass of material here provided and the original works to which he is referred. Precise description and quantitative treatment by recognised scientific method is much needed in this branch of geography, and Miss Semple has placed English-speaking geographers under a deep obligation by her scholarly treatment of the influences of geographical environment. It is for them now to carry forward the investigation into specific instances in order to determine the value of the different factors involved in each case, so that human geography may be as precise and definite in its methods and its results as the physical branch of the subject. To this end accurate and well-designed maps are of great assistance in representing the distribution of data, and we must regret that most of those in the present work are not satisfactory; the drawing is coarse and the scale is indicated by the lines of latitude and longitude only. Printed on suitable paper line blocks give excellent results, and looking at those which illustrate German text-books on this and other subjects, it is to be desired that they should be employed here to better advantage.

\section{THE AMERICAN AND COUNTRY LIFE.}

The Country-life Movement in the United States. By Prof. L. H. Bailey. Pp. xi+220. (New York: The Macmillan Co.; London: Macmillan and Co., Ltd., I9Ir.) Price $5 s$. $6 d$. net.

TO the untravelled Englishman, who still looks upon money-making and hustling as the natural habit of the American, the steady outflow of books from the United States dealing with the country and with country life comes as a great surprise. But those who have had the privilege of meeting the American in real life know that he, too, like the Englishman, has an inborn love of the country, which has not been killed off even by a couple of generations of town life, and is now asserting itself more than at any time in our previous history. Indeed, this 